http://garmian.edu.krd

https://doi.org/10.24271/garmian.142

\title{
Effect of overlap technique on hardness and fatigue behavior in ND-Glass laser heat treatment of carbon steel
}

\author{
Samir Khudhir Al-ani, Nada A. Khattab \\ Baghdad university - college of science for women - Physics Department \\ E-mail: smsddzzz@yahoo.com
}

\section{Synopsis}

Laser surface heat treatment has been accepted as an effected method of surface hardening of steels, laser beam provides the extra advantage of hardening localized region in intricate engineering component.

Fatigue strength is a surface phenomenon although factors such as microstructure, residual stresses affect the fatigue strength, surface condition if not favorably prepared is detrimental to the fatigue behavior.

ND-Glass laser pulses were applied to 0.35 carbon steel specimen, the overlapping of laser pulses mentioned has resulted in low surface roughness and increase surface micro hardness $(800 \mathrm{Hv})$. The fatigue strength was found to be increase by $6 \%$ due to overlapped laser treatment.

\section{Keywords: Nd-glass laser, carbon steel, microhardness, fatigue}

\section{Introduction}

Laser hardening is known for some times now, but its use in metal processing and technology was not happening until (1970's). Laser surface hardening is known to induce face transformation and probably forming favorable compressive residual stresses that would enhance the surface properties of the treated steel.

The engineer faced a state where it is desirable that the component should have a surface properties differing from those of its interior, therefore core with high strength and sufficient toughness, to take up the mechanical forces combined with high surface hardness to combat wear are needed. This requirement cannot be satisfied by one material $(1,2)$. The direction is turned to surface treatment as the only means of achieving this ends.

Laser technology is opening up new technically and economically attractive possibilities for the surface treatment of metallic and ceramic materials. Laser surface hardening involves localized heating of a steel surface followed by self quenching that would cause the austenite to transform to martensite in this case the bulk of the material acts as a heat sink. 
The transformation hardening due to laser beam was studied by many workers. The resulting phases in the microstructure depend upon the laser beam characteristics and on the composition of treated steel. Noticeable increase in micro hardness was also fond due to laser treated (3). However scatter in surface micro hardness expected when microstructure is not uniform and when hard component form due to laser glazing.

Laser hardening response of steel as expects increase with the carbon content $(4,5)$. When the energy and diameter of the laser beam are adjusted to transform the surface of austenite, self quenching by conduction into the cold metal beneath the surface transform of austenite to martensite. This process gives a hard layer resistant surface with less distortion that caused by flam or induction hardening $(6,7)$.

The use of lasers for metal surface processing has several advantages;

- The process is cheaper than either bulk alloying or through hardening heat treatments.

- Surface processing may be done rapidly with minimal distortion of the overall shape.

- Regulated amount of energy may be delivered to a surface with precise spatial and temporal control.

- Hard to reach places may be treated.

- No external quenching is needed.

\section{Experimental}

ND-Glass pulse laser were applied to carbon steel specimens. Overlapping laser pulses technique used to produce low surface roughness with high surface hardness to improve the fatigue strength.

Carbon steel with chemical composition give in table 1 was used; fatigue test specimen geometry and dimensions are given in figure (1).

\section{Table ( 1): Chemical composition of carbon steel.}

\begin{tabular}{|r|r|r|r|r|r|r|}
\hline $\mathrm{C}$ & $\mathrm{Si}$ & $\mathrm{Mn}$ & $\mathrm{Ph}$ & $\mathrm{S}$ & $\mathrm{Cr}$ & $\mathrm{Al}$ \\
\hline 0.35 & 0.183 & 0.63 & 0.03 & 0.05 & 0.07 & 0.03 \\
\hline \multicolumn{7}{|c|}{} \\
\hline $\mathrm{Mo}$ & $\mathrm{Cu}$ & & & & & \\
\hline 0.02 & 0.16 & & & & & \\
\hline
\end{tabular}




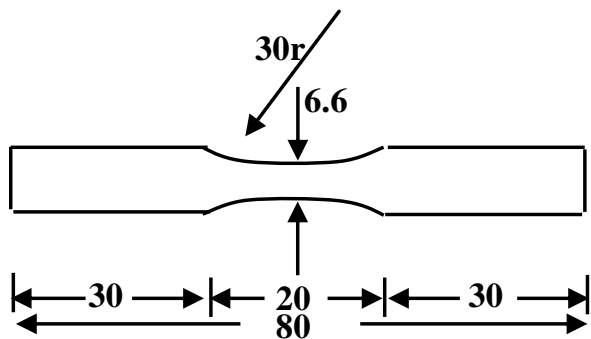

Figure( 1): Test specimen geometry and dimension (all in $\mathbf{m m}$ ).

Irradiation was carried out by means of overlapping pulses of ND-Glass laser (wave length $1.06 \mu \mathrm{m}$, energy $6 \mathrm{~J}$, power 55000 watt, pulse time $20 \mathrm{nsec}$, and power density $11700 \mathrm{w} / \mathrm{mm}^{2}$ ).

Fatigue test of treated and untreated specimens was carried out on rotating bending fatigue machine with cantilever bending, step loading test was adopted though out the investigation. However probity test was carried out on few best specimens to verity that others was no effect on step loading on the fatigue strength of the tested steel, test was carried out at constant frequency of $12000 \mathrm{rpm}$. Overlapping technique with $2 \mathrm{~mm}$ overlapped laser pulses is applied.

\section{Result and discussion}

The microstructure and depth of hardening of laser treated specimen is shown in figure (2), this figure show the cross section image of treated layer with thickness about 80 micrometer.

Micro hardness values distribution of two overlapped ND-Glass laser pulses is shown in figure (3), the energy distribution of laser pulses is not uniform therefore micro hardness values varied with significant scatter, overlapping can be used to obtain better micro hardness distribution (up to $700 \mathrm{Hv}$ ).

Figure (4) show the depth of hardening, the transformation of surface from liquid state to solid state in very short time may result an increase in hardness due to laser glazing for some area in which glazed phase was formed, in addition the fast heating and cooling without melting caused internal compressive stresses $(1,4)$. Beside these effects with martensite and cementite formation would increase the hardness. The results of micohardness give favorable values when compared with published references (8). 
Fatigue test result indicates that the laser treatment by overlapped ND-Glass laser pulses is improved fatigue behavior. Figure (5) show the fatigue test result ( $\mathrm{S}$ $\mathrm{N}$ curve) it can be seen from the figure that laser treatment with overlap technique increase the endurance limit by about $6 \%$ over that due to non treated sample, this is believed to be due to laser effect which could have favorably induced compressive stresses and therefore improve the fatigue resistance. This values of fatigue limit which have been, put forward in the present work give favorable values when compared with published references (9).

\section{Conclusion}

1. ND-Glass overlapped laser processing on the surface of $0.35 \% \mathrm{C}$ steel is found to increase the micro hardness values of the treated surface (up to $700 \mathrm{Hv})$.

2. Laser processing of carbon steel give a hard martensitic structure.

3. In fatigue test of treated and untreated samples the endurance limit was found to be increase by $6 \%$ due to overlapped laser treatments.

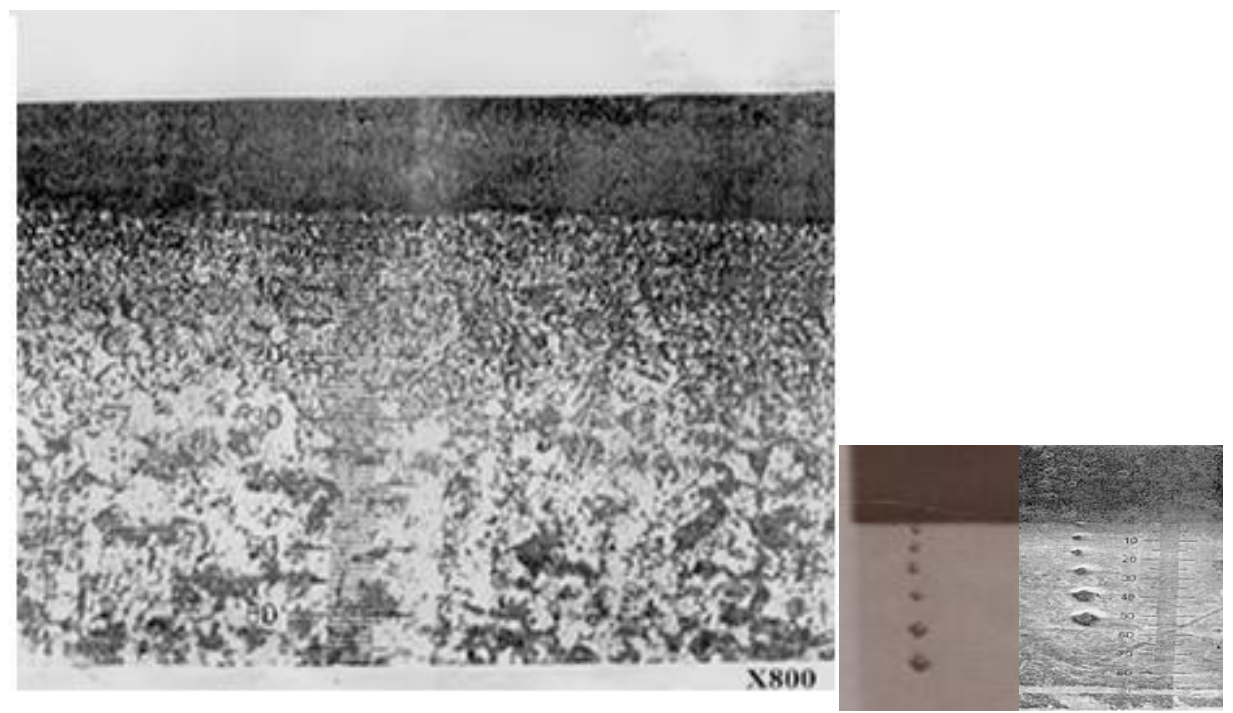

Figure (2): Microstructure and depth of hardening of laser treated specimen. 


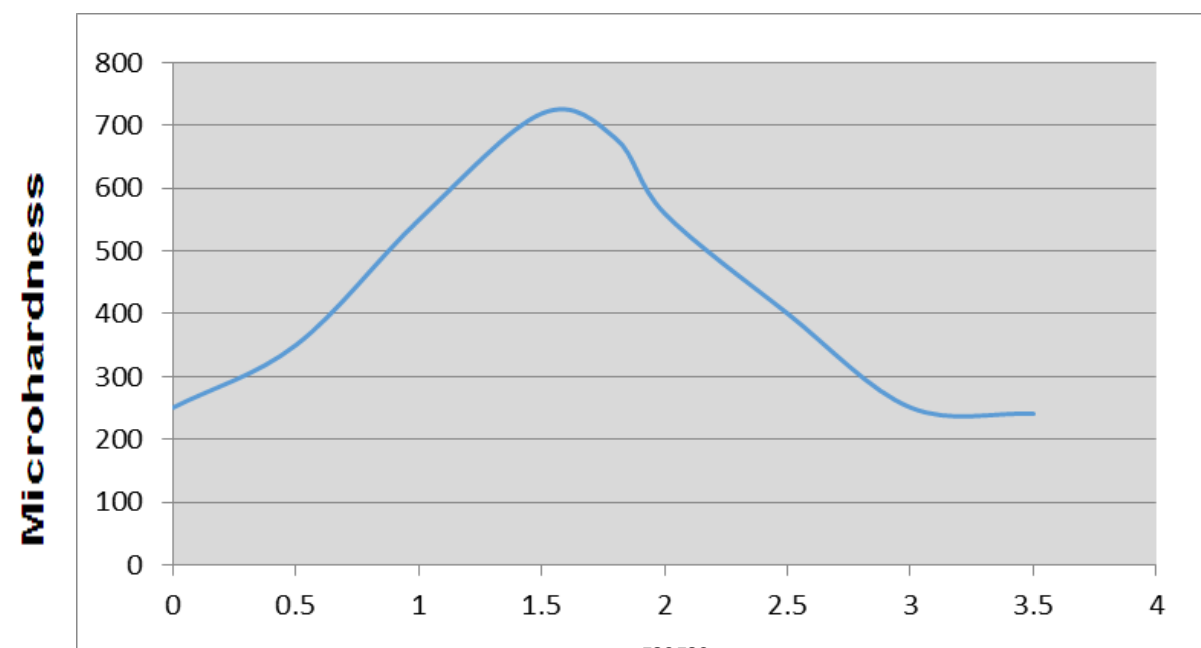

Figure (3): Micro-hardness values distribution of two overlapped ND- Glass Laser pulses.

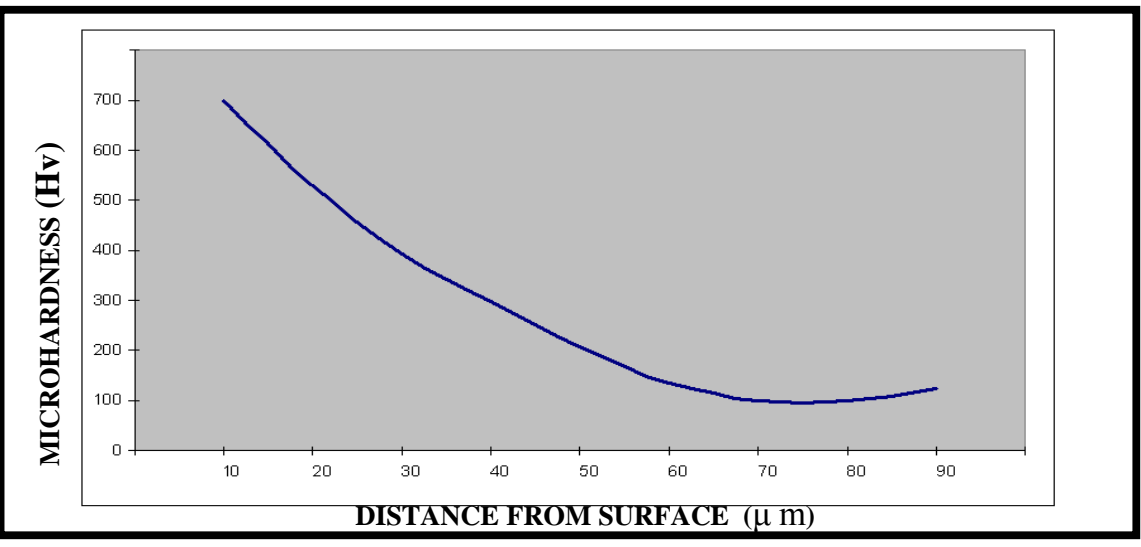

Figure (4): Depth of hardening.

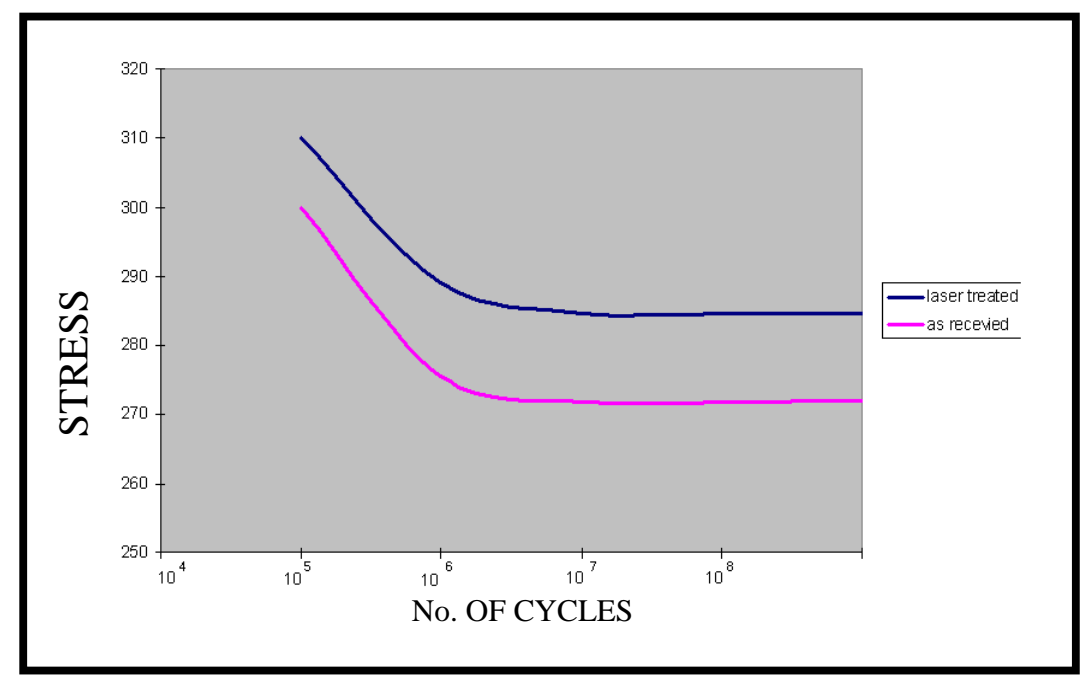

Figure (5): S-N Curve for treated and untreated samples. 


\section{References}

1. Migliore L. (1996). "laser material processing “, Marrel Dekker, New York, P.66, pp 209-212.

2. Bykalin N. , Vglov A., Kokora A. (1988), “Laser machining and weliding”, Mir Publishers, Moscow.

3. Al-ani S. K., Ahmad A.K. , Hasoon S.A. (2000)" Effect of laser beam energy on the hardness of carbon steel", Al-Nahrain university magazine,(4):60-64.

4. Bradly R. John and Kim Sooho. (1988), "Laser transformation hardening of iron and iron carbon-chromium steel" , Metall. Trans. 19A,P 2013-2025, August.

5. Al-ani S. K. . (2002), "Improvement of surface hardness and wear resistance for low carbon steel using laser beam", Journal of college of education for women, Baghdad university, Vol.20, no.2, (2009).

6. Tsay L. w., Lee W. C. and Wu J. K.(2006), Effect of hydrogen environment on the notched tensile properties of T-250 maraging steel annealed by laser treatment", Corrosion Science, 44(6):1311-1327.

7. Yue T. M. , Yu J. K. and Man H. C. ,(2011), “ The effect of excimer laser surface treatment on pitting corrosion resistance of $316 \mathrm{~S}$ stainless steel ", Surface and coating technology, 137(1):65-71.

8. S.R. Al-Sayed, A.A. Hussein , A.A. Nofal, (2017)," Characterization of a Laser Surface-Treated Martensitic Stainless Steel", Materials 2017, 10(6): 595.

9. Ye. Chang, (2011), "Fatigue performance improvement in AISI 4140 steel by dynamic strain aging and dynamic precipitation during warm laser shock peening", Acta Mateials, 59(3):1014-1025. 